\title{
Clinical sympathy: the important role of affectivity in clinical practice
}

\author{
Carter Hardy ${ }^{1}$
}

Published online: 27 March 2019

(c) Springer Nature B.V. 2019

\begin{abstract}
Bioethics has begun to see the revaluation of affects in medical practice, but not all of them, and not necessarily in the sense of affects as we know them. Empathy has been accepted as important for good medical practice, but only in a way that strips it of its affectivity and thus prevents other affects, like sympathy, from being accepted. As part of a larger project that aims at revaluing the importance of affectivity in medical practice, the purpose of this paper is to develop a clinical sympathy that can serve as a trainable skill for medical professionals. While everyday sympathy may be problematic as a professional skill for physicians, this does not imply that sympathy should be entirely rejected. As a natural part of our moral psychology, sympathy is an intersubjective affect that aids in our interactions with others and our decision-making abilities. I present here a theory of clinical sympathy as an affective response to patients, in which physicians are both attuned to their affective response and understand how their affects are influencing their beliefs and judgments. In this way, clinical sympathy serves as a trainable skill that can aid physicians in their interactions with their patients.
\end{abstract}

Keywords Sympathy $\cdot$ Bioethics $\cdot$ Empathy $\cdot$ Affectivity $\cdot$ Detached concern

There has been a renewed interest in affectivity in recent years, such that even science-focused fields like medicine are reexamining affects like emotions, feelings, and moods. ${ }^{1}$ Specifically, there has been a lot of work done recently on the importance of empathy in the process of providing better patient care. This is certainly a step in the right direction for bioethics, since increased empathy has been shown to correspond to heightened feelings of fulfillment in physicians (Halpern 2014, p. 304; Larson and Yao 2005; Shanafelt et al. 2005), and increased feelings of care in patients (Derksen et al. 2013; Halpern 2014, p. 303). Many have also argued that empathy leads to better treatment of patients and a greater respect for autonomy due to the increased attention that empathy brings to the physician's understanding of a patient (Eikeland et al. 2014; Derksen et al. 2013; Di Blasi and Kleijnen 2003; Halpern 2001; Hojat et al. 2011, 2013; Hooker 2015; Pedersen 2008; Roter et al. 2006). However, this paper is not about clinical empathy. This topic has already been discussed extensively by many. Instead of being

Carter Hardy

chardy@ut.edu

1 Department of Philosophy and Religion, University of Tampa, 401 W Kennedy Blvd, Mailbox R, Tampa, FL 33606, USA the focus of this paper, I take empathy to be an example of what can and should happen in bioethics concerning other moral emotions. Specifically, this paper will focus on sympathy and how it can (and should) be revalued and redefined to be a useful medical skill. This may not be intuitive for many, so I will begin by addressing some general questions:

1. What has changed about the understanding of empathy that has allowed it to be accepted in medicine?

2. Why was sympathy, a similar moral emotion, excluded from this revaluation?

${ }^{1}$ I prefer to use the term affectivity when talking about individual affects since I do not think there is a clear divide between an experience being an emotion, feeling, and mood. Rather, individual affects, like happiness, tend to be experienced as emotions, feelings, and/or moods. Especially when it comes to empathy, which has many competing definitions and explanations, identifying it with one type of affect-such as an emotion-would oversimplify the experience of empathy. To make things more complicated, there are different theories of emotions, feelings, and moods, and empathy could be fit into any one of these. However, this paper is about sympathy, not empathy, so arguing for a specific theory of emotion and how empathy either does or does not fit this theory, is outside of the scope of this paper. Especially since empathy is now more associated with a cognitive skill/faculty than and affective experience, it may even be fruitless to provide such an argument. Instead, in this paper, I am accepting the current theory of empathy as a cognitive understanding of the other, and approaching sympathy considering this interpretation of empathy. 
3. How can sympathy be similarly changed to also be accepted as useful for medical practice?

Answering the first question is important because it will show how and why empathy was revalued in medicine while sympathy and other affects were not. However, before this can be answered in the sections below, it is worth noting the change in the way empathy has been defined. The definition of empathy has changed many times throughout its history, making it a difficult term to define. While it would likely be an exaggeration to claim that all medical professionals defined empathy in the same way, the most prominent definition of empathy in the early twentieth century was as follows:

Traditional clinical empathy: a feeling that physicians have either towards a patient (like pity) or with their patients (like sympathy or emotional contagion).

This definition remains prominent, even today. However, in the past few decades, there has been a shift to defining empathy in a more cognitive way. That is, rather than being understood as a bodily feeling, empathy is defined as a mental process that allows us to understand others. For the purpose of this paper, I will focus on the more specific definition of cognitive empathy that is used in bioethics:

Simulation clinical empathy: an understanding of the other acquired when we either consciously or subconsciously simulate in our minds what it would be like to be the other. The simulated understanding of the other's thoughts, beliefs, and feelings are then projected back into other. ${ }^{2}$

While there are certainly many other theories of empathy, ${ }^{3}$ simulation theory (henceforth ST) is the most prominent theory in contemporary discussions of empathy. In this form, it is an understanding of the other, which means that it is essential for better understanding others. ${ }^{4}$ It is meant to serve as a supplement to the naturalistic methods more commonly used to understand patients in medicine.

\footnotetext{
2 This is elsewhere called merely the simulation theory of empathy. It will be explained further in later sections of this paper.

3 These include theory (Baron-Cohen 1993, 1995; Gopnik 1988, 1993, 1996; Gopnik and Meltzoff 1997; Gopnik and Schulz 2004; Gopnik and Wellman 1992; Karmiloff-Smith 1988; Kitcher 1988; Wellman 1990; Wellman et al. 2001), and interaction theory (Gallagher 2001, 2004, 2009, 2012; Gallagher and Hutto 2008).

${ }^{4} \mathrm{I}$ phrase this as such since, even with the way empathy is being defined, it is still possible to understand parts of the other's situation without empathy. Empathy allows for a more holistic understanding, but there is still an understanding of some aspects of the other's situation without empathy.
}

This shift from the traditional theory to the simulation theory is important because it transitioned empathy from being a passive, affective experience-one that merely happens to us-into an active, cognitive skill that can be trained and improved. Whether or not we agree with the definition of empathy, the recognition of an affect as important for medical practice was a serious change in the earlier paradigm that chastised any appeals to affective experiences. To be clear, I reject this definition of empathy as a simulated understanding and instead favor narrative-based theories of empathy. However, the reasoning for this would be better left to be the focus of another paper. For this paper, I will continue to talk about empathy as a simulation, and support the general revaluing of empathy in medicine. However, this revaluation is not without its problems, such as the continued rejection of affectivity in general.

Answering the second question is important because it will demonstrate why sympathy, when defined in the everyday sense was seen as inappropriate for medicine. Sympathy, like empathy, is a specific kind of intersubjective affect. In bioethics, it has most often been defined in the exact same ways as traditional clinical empathy —as a feeling that physicians have either towards their patients or with their patients. Moving forward, the real trick to answering the second question will be explaining why empathy has been entirely associated with its cognitive aspects, allowing it to be revalued in medicine, while sympathy has been entirely associated with its affective aspects, causing it to still be rejected in medicine-despite both empathy and sympathy being cognitive-affective experiences. The cause for this rejection is the set of problems that arise from a merely everyday sense of sympathy.

Answering the third question is important because it will allow not only sympathy, but also other affects, the chance to be revalued as useful for medical practice. I argue that the main problem with the acceptance of empathy isn't its acceptance, but that its acceptance doesn't solve all of the problems that it was mean to solve. For example, if we accept the current conception of empathy as an understanding of the other achieved through simulation and projection of mental states, then this still leaves a gap in the physician's understanding of the patient. This gap is the understanding of the affective interaction with the patient. It is one of the gaps that empathy was meant to fill, but has failed to do so. For this reason, redefining sympathy so that it may be revalued in medicine will hopefully fill some of the gaps left by clinical empathy.

In sum, I argue here that it is possible to refine a clinical sympathy that can serve as a trainable skill for medical professionals. I agree with others that it would likely be fruitless to argue that everyday sympathy should simply be incorporated into medicine, where everyday sympathy is merely our emotional response to the other's emotional state. 
Taken in this sense, it was not entirely wrong for medical students and professionals to worry about an overly-strong emotional investment in their patients, or the possibility of emotional burnout from sympathizing and empathizing with every patient they encounter (Ekman and Halpern 2015; Eikeland et al. 2014, p. 5; Hooker 2015, pp. 542-544; Testerman et al. 1996). However, the validity of these fears does not imply that sympathy should be entirely rejected. As a natural part of our moral psychology, sympathy is an intersubjective affect that aids in our interactions with others. It is always present in our experiences of other subjects and can be very useful in our decision-making. Rather than an outright rejection of sympathy, we need a better understanding of it so that we can identify and refine it into a skill that will be useful for physicians. In order to answer the above questions completely, this paper will proceed in five parts.

First, I provide an explanation for everyday sympathy based on Scheler's phenomenology of sympathy. While there are other theories of sympathy, I take Scheler's theory as being the best suited for developing a clinical sympathy. Second, I explain the ways in which empathy has been revalued in both medicine and bioethics, but in such a way that it is appropriated into the naturalistic attitude of medicine and conceptually separated from any of its possible affective aspects. In this way, medicine's tendency towards an ideal of detached concern is maintained and other affects are able to be rejected as being importantly different from empathy. Third, I address the problems that arise in a system that idealizes a lack of affectivity. These problems are perpetuated by the appropriation of empathy into medicine. Overcoming these problems requires a rejection of detached concern and the revaluation of affectivity in general. Fourth, I explain how sympathy as it is experienced in our everyday lives can have both positive and negative effects on our lives. I focus on the problems sympathy would have for medicine if it was adopted, since these are the problems that clinical sympathy will need to overcome. Finally, I provide a theory of clinical sympathy that is capable of overcoming most of the problems with everyday sympathy. While there are still some problems that clinical sympathy will need to overcome, this will hopefully serve as step in the right direction towards revaluing sympathy and affectivity in medicine.

\section{What is sympathy?}

There are no set definitions for empathy and sympathy. Different philosophers have different theories for each, and it is not uncommon for the same experience to be called empathy by some and sympathy by others. As Lanzoni notes, in English articles that reviewed Theodore Lipps' work on Einfühlung, "the preferred term was most commonly 'aesthetic sympathy' and sometimes merely 'sympathy,", demonstrating the ease with which these two terms could have been translated otherwise (Lanzoni 2012, p. 306). ${ }^{5}$ Here, I will adopt Scheler's theory of sympathy since it is distinctly different from the way in which empathy has been defined.

In his work The Nature of Sympathy (1954), Scheler talks about several important intersubjective affects, including emotional sharing (Mitfühlen), sympathy (Mitgefühl), emotional contagion (Gefühlsansteckung), and a feeling of oneness (Einsfühlung) (Scheler 1954, p. liii, 12, 1992, p. 59). ${ }^{6}$ He defines sympathy as a "fellow-feeling 'about something'; rejoicing in his joy and commiseration with his sorrow" (Scheler 1954, p. 12). It is an understanding of the other's affective state with the addition of an affective response. Specifically, one's own affect has the other's affective state as its intentional object. I will call this everyday sympathy, which I will define as such:

Everyday sympathy: a feeling that has the other subject's feelings as it's intentional objects.

For instance, if my friend gets a promotion and he is joyous about it, then a sympathetic reaction from me may be to feel happy for my friend's happiness. However, this example may be a little misleading, since there need be no matching between the affects (Scheler 1954, pp. 13-14). One could also be sad or angry about the other's happiness and it would still fall into the realm of sympathy. Hence, sympathy is distinguished from directly sharing in someone's affect because, in sympathy, "my commiseration and his suffering are phenomenologically two different facts, not one fact," as

\footnotetext{
5 Similarly, "empathy" has different meanings in English than simply the imaginative, projective empathy that Titchener and others discussed. For now, it is worth noting-as both Lanzoni and Andrea Pinotti note - that "there was never one simple psychological depiction of Einfühlung or empathy: projection, transfer, association, animation, personification, vivification, fusion, identification, among others were all possibilities" (Lanzoni 2012, p. 306; Pinotti 2010, p. 94). Philosophers and psychologists have been unable to agree to one use for the term. This has led to the debate concerning the true nature of empathy.

${ }^{6}$ While many like to think that the experience of most (if not all) affects is independent of the existence of other subjects. For Scheler, most affects are made possible by our primordial intersubjectivity, and we experience them with others. That is, we are always, already being with others in the world, and it is only within this context the we experience affects. As such, he sees love and sympathy as fundamental features of the lives of persons. Affects are perceptions of values, and they can be divided into levels based on the things in which they perceive value, as well as how such value is perceived. Intersubjective affects-especially sympathy-allow us to experience affects with and for others, sometimes to the extent that we merge back into our primary intersubjectivity by achieving a feeling of oneness with each other. In this way, our affective lives are an important aspect of our intersubjective lives because they allow us to experience a valued world with others.
} 
opposed to what is happening in emotional sharing (Scheler 1954, p. 13).

Additionally, in order to understand the nature of sympathy, Scheler stresses the need for a distinction between "vicariously visualized feeling, and participation in feeling" (Scheler 1954, p. 14). In other words, it is possible to understand the other's feeling without experiencing that feeling oneself. It is this kind of insight that contributes to the idea of clinical empathy as a cognitive skill rather than an affective experience. For instance, I can see that the other is angry and fully understand that the other is angry, without ever needing to feel anger myself. The feeling of the other's feeling (in either emotional sharing or emotional contagion) is a separate phenomenon from the understanding of the other. If this distinction is not made, then sympathy could easily be confused with either emotional sharing or emotional contagion.

To further demonstrate this distinction, Scheler uses the example of "the cruel man" (Scheler 1954, p. 14). This is actually an example of the opposite of what Scheler calls genuine sympathy (Scheler 1954, p. 14), ${ }^{7}$ but it still shares the same structure as sympathy. The cruel man's enjoyment is based on the suffering of the other. He must understand the suffering of the other, as well as care about the other's suffering, in order to enjoy the other's suffering. However, because he is feeling enjoyment while the other is suffering, this shows that there is a distinct disconnect between the understanding of the other's mental state and experiencing the same state as the other. In other words, the understanding and the participation in the affective state are separate.

Relating to this point, sympathy can be distinguished from a feeling of oneness with others due to the distance that sympathy allows between the self and other (Scheler 1954, p. 23). The common worry about sympathy is that is causes too close of an emotional connection between physician and patient. However, this is not true. Sympathy is not emotional contagion; it is neither perspective-taking nor the melding of two subjects' emotional experiences into one. There is a space between the subject and the other that allows one to respond emotionally to the other without directly experiencing the same emotion oneself. In sympathy, I can feel a wide variety of affects towards others, but this doesn't mean that I truly identify myself with them.

It is clear in his work that Scheler sees all intersubjective affects as interesting, important, and in need of being described. Each form has a very important role that it plays in our everyday, intersubjective lives. Since we are only focused on sympathy here, it is worth noting the importance

\footnotetext{
${ }^{7}$ Genuine sympathy is sympathy guided by love-when it is "embedded in, and sublated by, love" (Vandenberghe 2008, p. 39). This is important to the development of clinical sympathy.
}

of sympathy in that it allows us to be affected by other's emotions, feelings, and moods. We do not neutrally approach other's affective lives, but have our own affective reactions to them. They matter to us like anything else in the world can matter to us. ${ }^{8}$ In this way, sympathy helps fill in some of the intersubjective gaps left by empathy, especially in the way empathy is defined in medicine.

This importance of sympathy to our everyday lives does not necessarily mean that it has a place in medicine, nor does it mean that it is a trainable skill. There are still some problems with sympathy that make it a poor fit for medicine. For it to be accepted as part of the moral attitude of medical professionals, these problems will need to be overcome. Only in doing so can sympathy be refined into a clinical sympathy. By examining the history of clinical empathy, we can better understand both why empathy has been redefined to lack affectivity and how sympathy can likewise be redefined so as to be accepted by medical professionals while still maintaining that it is an affect.

\section{Empathy, medicine, and affectivity}

The discussion of empathy has a vital part to play in our current understanding of sympathy. As I will show in this section, empathy was once regarded in the same way as sympathy-it was seen as an overly-affective experience that ought to be avoided. Over the last few decades, during the advent of the bioethics movement, there began to be a shift in medicine towards including empathy, which is still taking place today. However, this revaluation has been largely limited to the discussion of empathy alone. Other affects that are similarly important to our intersubjective lives continue to be held at arm's length. The reason for this is that empathy went from being equated with an affective experience of the other's emotions to being equated with the cognitive skill of detached concern. Empathy was welcomed into medicine, while sympathy - which is still understood in medicine as an affective experience-remains unimportant, and possibly dangerous.

To begin this discussion, empathy has been discussed as a means to overcome a number of problems in medicine. These problems include professional burnout, a lack of understanding for patients' perspectives, and a lack of

\footnotetext{
8 Aside from the intersubjective importance of sympathy and empathy, emotional sharing allows us to genuinely share an emotion with the other. It is our ability to enter into the same situation as the other in the world - to literally "be with" others in an affect. Additionally, emotional contagion has a special role in the way that it bonds us to the world with others. It shows how we are pulled into the same affective world with others, even if we do not realize it happening. Finally, a feeling of oneness brings us back to our primary intersubjectivity.
} 
attunement to patients' affects. Many of these problems arise during the education and training for medical students (Eikeland et al. 2014; Hojat et al. 2009). Students both actively and passively learn to avoid affective experiences (which used to include empathy) in order to become medical professionals. The training to become a professional is a demanding process that requires the memorization of a lot of information and many new skills in a short period of time. In order to learn all of the information necessary to make good medical judgments, some other knowledge and skills, such as emotional skills, must be neglected (Eikeland et al. 2014, p. 4; Hojat et al. 2009, p. 1188). Specifically, students feel the need to foster those skills that will make other professionals accept them. They find role models to emulate, which further leads to the avoidance of affective reactions (Eikeland et al. 2014; Marcus 1999; Skeff and Mutha 1998).

The theory of empathy that is proposed to overcome these problems is ST, as defined above. To reiterate here, this theory argues that empathy is an understanding of the other's mental states, and this understanding is acquired through a kind of simulation of the other's mental states within one's own mind (Gallese 2001, 2003; Goldman and Sripada 2005; Goldman 2006; Meltzoff 2006). When I perceive the other's body, I simulate within myself what it would be like if I were in the other's situation. I then reference the mental states that arise in myself, assume that these are what the other must be experiencing, then project $t$ them back into the other. In this way, I attribute the simulated mental states to the other and thus understand them from my own perspective. As Goldman says, ST is a "strategy of imagining one's own thoughts, feelings or behaviours in a situation similar to the target, which involves using self-reflection as a tool to understand... mental states" (Goldman 2006, p. 162). While there are several different varieties of ST, the main idea remains the same, that we create simulated models to understand the minds of others (Gallagher 2012, p. 355; Gallagher and Hutto 2008, p. 176). This theory was meant to explain how empathy provides an understanding of the patient's perspective while maintaining an emotional detachment such that the physician understands the mental state of the patient without actually experiencing that same state. Physicians are supposed to place themselves "in their patients' shoes" and simulate the thoughts, beliefs, and feelings of their patients. Empathy in this sense is not a feeling or an emotion, but a cognitive process of trading places with the patient in hopes of better understanding the patient.

While there are some problems with the contemporary definition of empathy-a topic I address in another paper (Hardy 2017) — that empathy is being discussed at all is still a step in the right direction. The problem isn't the acceptance of empathy, but rather the way in which its acceptance has perpetuated the ideal of detached concern. It is this ideal that has blocked the acceptance of other affective experiences like sympathy.

The ideal of detached concern has dominated much of medicine since Renée Fox's and Howard Lief's work, though I will focus specifically on the ways that it affects the relationship between physician and patient. The term detached concern comes from Fox's work Experiment Perilous (1959), and was further addressed in a later article by Lief and Fox (1963). Though, as a professional approach to patients, detached concern was also encouraged by others (Merton 1957; Osler 1899, 1904). As Fox argues, the physician is supposed to be both "sufficiently detached or objective toward the patient to exercise sound medical judgment and maintain his equanimity," as well as "sufficiently concerned about the welfare of the patient to give him compassionate care" (Fox 1959, p. 86). These are supposed to be maintained in a delicate balance (Fox 2006, p. 945; Lampert and Jürgen 2016, p. 16; Underman and Hirshfield 2016 , p. 95). Being entirely detached-both approaching the patient as an object of scientific study and lacking empathy_risked being too cold and misunderstanding the patient's condition. However, being overly concerned, and affectively engaged with the patient was understood to be equally as risky. Additionally, medical practice is filled with "emotion-laden experiences" that can wear on physicians who are unable to detach from them (Lief and Fox 1963, p. 13). ${ }^{9}$ If emotional responses were allowed into medicine, then it was feared that they would corrupt the objectivity of the physician's findings (Cadge and Hammonds 2012, p. 2690). The general goal as outlined by Lief and Fox was to set aside one's affective responses to the patient, as well as properly manage the patient's affects so as to acquire the best, objective understanding of the patient's condition (Lampert and Jürgen 2016, p. 3; Underman and Hirshfield 2016, p. 95; Yagil and Shnapper-Cohen 2016, p. 1694). At the same time, the physician needs to maintain an appearance of caring, so as to resist hardening one's heart towards patients (Underman and Hirshfield 2016, p. 95). ${ }^{10}$ Physicians need to maintain affective distance while simultaneously appearing to be concerned about the patient's wellbeing (Fox 2006, p. 945; Halpern 2007, p. 696, 2012, p. 41; Yagil and Shnapper-Cohen 2016, p. 1694). ${ }^{11}$ As Lief and Fox say,

\footnotetext{
${ }^{9}$ Lief and Fox list: "exploring, examining, and cutting into the human body; dealing with the fears, anger, sense of helplessness, and despair of patients; meeting emergency situations; accepting the limitations of medical science in dealing with chronic and incurable disease; being confronted with death itself." (Lief and Fox 1963, p. 13).

10 As Halpern says, it is "detachment with a veneer of generic tenderness" (Halpern 2001).

11 Detachment is trained to assist with emotional experiences, such as death and dying (Fox 2006, p. 945; Lief and Fox 1963, p. 13; Underman and Hirshfield 2016, p. 95). And it is argued that it taken
} 
"the empathic physician is sufficiently detached or objective in his attitude toward the patient to exercise sound medical judgment and keep his equanimity, yet he also has enough concern for the patient to give him sensitive, understanding care" (Lief and Fox 1963, p. 12).

To be fair, Fox did stress the importance of both detachment and concern (Lief and Fox 1963), but the emphasis in contemporary medicine has become more focused on detachment, while discouraging concern (Cadge and Hammonds 2012, p. 267; Fox 2006, p. 945; Lampert and Jürgen 2016, p. 1). ${ }^{12}$ At best, concern has become largely concern for resolving the patient's problems, and less specific concern for the patient as a patient. In other words, concern has been more associated with "interest," rather than "care." When medical students and physicians veer closer to concern (read care) than detachment, it is seen as a "failure to cope" (Cadge and Hammonds 2012, p. 267). As such, "students learned early on in their training that they cannot and should not talk about their emotions, especially not to faculty" (Underman and Hirshfield 2016, p. 95). ${ }^{13}$ This is primarily due to the primacy of the naturalistic attitude in medicine.

By naturalistic attitude, I mean the attitude that typically guides the sciences and which focuses exclusively on objectivity and detachment in order to best understand and judge a situation (Carel 2011; Zahavi 2014a, p. 135; 2014b, p. 127). In the medical field, the naturalistic attitude condemns affectivity and interpersonal connections, while encouraging scientific objectivism (Eikeland et al. 2014, p. 4; Singh 2005; Khanuja et al. 2011, p. 37; Pedersen 2010, pp. 598-599). In terms of intersubjective understanding, the naturalistic attitude is when we treat others as if they are composed of two parts: "the other's body is given to us as a material unity, and functionally dependent upon and located in this material object; the other's experiential life is then posited as a founded stratum" (Zahavi 2014b, p. 127). That is, others are studied in a scientific manner-divided into what can be directly observed and studied, and that which must be inferred from the observable. As a result, everything of importance in the process of understanding others is reduced to the physically observable. It is this focus on merely the physically observable in the naturalistic attitude that causes

\footnotetext{
Footnote 11 (continued)

on partly due to the examination of cadavers during autopsies (Underman and Hirshfield 2016, p. 95).

12 This is understood to be a useful coping technique for students to learn. (Fox 2006, p. 945).

13 These authors also note that students "made jokes or blamed the patient to reduce their anxiety. This kind of emotional socialization led to dehumanizing and objectifying patients" (Underman and Hirshfield 2016, p. 95). In these ways, students foster detached concern as way to cope with emotion-laden experiences.
}

physicians to idealize detached concern (Eikeland et al. 2014, p. 3; Gelhaus 2012a; Halpern 2011; Hojat et al. 2009, pp. 1188-1189).

There is nothing inherently wrong with the naturalistic attitude in itself. This attitude has been incredibly useful, especially in the medical field. It has allowed for the rapid improvement of medical technology, research, and treatments. It is hard to deny the importance of these improvements. The problem with this attitude only arises when it is taken to be the only important attitude, as if it is the only means of finding truths (Landes 2012a, p. xxxiii; MerleauPonty 2012, p. lxxii, 452). When it comes to our understanding of others, it is important to not limit our understanding to the naturalistic attitude (Zahavi 2014b, p. 127). Patients are multifaceted subjects that cannot be best understood through a single, reductive attitude.

The naturalistic attitude causes us to break with our everyday experiences of the world, and experience all phenomena as things to be "methodically 'observed' and systematically 'constructed' as 'facts"' (Vandenberghe 2008, p. 26). It causes us to explain things in ways that we have never experienced them, because we assume that they are more real under scientific observation than in our ordinary, everyday experience of them (Flaherty 2016, p. 115). Specifically, for detached concern, it treats the patient as only existing for the physician in an intellectual way that "denies the ongoing emotional field between patients and physicians" (Halpern 2001, p. 25). While this may be a good way to approach medical conditions in general, it is not the best way to approach the individuals who are suffering through those conditions. Medicine is an inherently intersubjective practice and to adopt an attitude towards patients that essentially strips them of their otherness and reduces them to something that can be methodically observed is not compatible with this intersubjectivity (Flaherty 2016, p. 113).

This, however, is exactly what happens in ST. Physicians are told that they need to empathize with their patients, that empathy will give them a better understanding of their patients, and that this understanding will lead to better care for their patients. Essentially, they are told that concern will lead to understanding. While this seems to bridge the gap between the physician and the subject, this is actually still an approach to the other as completely separate from oneself and only capable of being understood from one's own perspective. When we see others as objects for scientific observation-especially when already entrenched in the naturalistic attitude-it seems obvious that simulations and inferences give us an understanding of the "real" other that is somehow missed in ordinary perception. Again, this may sometimes be a very useful way to understand others, but it is not the only way and it should not be treated as such.

Empathy was supposed to be the experience that allowed physicians to acquire a more complete understanding of the 
other. However, as is evident by the prevalence of detached concern in medicine, ST only serves as an example of how predominant this naturalistic attitude has become, such that it infects even the solutions to the problem.

To summarize up to this point, the goal in physicianpatient interactions is to provide the best possible treatment, and for a long time it was assumed that affects would only cloud the physician's judgment. With the shift towards revaluing empathy to aid in patient understanding, it was redefined in a way that allowed it to be easily accepted. Specifically, defining empathy in line with detached concern makes it easy to incorporate empathy into medicine. Recommending an entirely new and somewhat foreign skill would most likely be met with more resistance than a skill that already fits with the physician's trained attitude. The physician's methods already work well without the addition of affective skills that may risk attachment. As Halpern explains, "the fundamental justification given for detachment and medicine is the argument that it enables doctors to understand patients' emotional experiences accurately, free from their own emotional bias" (Halpern 2001, p. 17). That is, medicine became refocused on detached concern for patients-as opposed to a genuine empathetic connection with them-as a way to help doctors avoid bias and emotional investment in patients. The physician is meant to understand affects in an unaffected way.

Trying to adopt a theory of empathy that fits this attitude perpetuates the problems caused by the lack of empathy rather than solves them. Rather than escaping the naturalistic attitude, detached concern and ST appropriate empathy into a purely cognitive skill that fits with the naturalistic attitude (Garden 2007; Halpern 2003; Macnaughton 2009; Pedersen 2008). Medicine has defined empathy in a way that is useful to its current attitude, maintaining the overall authority of the medical practitioner. It is just another scientific tool in the physician's naturalistic toolkit. In this way, ST of clinical empathy can be shown to merely perpetuate the problem it was intended to solve. ST is an overly cognitive theory of empathy that maintains the isolation between physician and patient, as well as the primacy of the physician's judgment of the patient's conditions. It is not an empathy that affectively engages with the other.

\section{The problems of detached concern}

There are at least four problems caused by the lack of affectivity in detached concern, which I draw out of Jodi Halpern's From Detached Concern to Empathy: Humanizing Medical Practice (2001). The first problem is that there is a lack of understanding for the patient's affects. This is related to the diversity problem (Gallagher 2012, p. 363), or that my simulated mental states are not necessarily an accurate representation of the other's mental states. Just because the physician imagines what it would be like if the physician was in the patient's shoes does not mean that the physician actually knows what the patient is going through. Especially when we are talking about the wide array of patients with whom a physician must empathize, it is not possible for a physician to fully understand all of the diverse perspective of different patients. When patients come from drastically different backgrounds or are suffering from conditions the physician has never come close to experiencing, a simulation simply cannot do the work of a complete understanding.

Essentially, because detached concern sets aside the importance of affective engagement in favor of cognitive comprehension, there is less interest in the affects of the patient. However, it would be unfair to claim that ST completely disregards the patient's affects. The recent prescription of empathy is meant to help physicians better understand patients' mental states, both affective and otherwise. On the other hand, the detached method involved in ST, which only allows the physician to understand the patient from the physician's own perspective, results in the diversity problem - that the patient is only understood as what the physicians can simulate in themselves. While detached concern causes physicians to believe they are understanding their patients' affects, this is actually untrue and misleading (Flaherty 2016, p. 113).

The second problem, which is more specific to detached concern, is that detached concern causes a lack of attunement to one's own affects. Again, the ideal is that physicians understand their patients' affects while being unaffected themselves. They need to manage both theirs and their patients' affects. The result is a belief that physicians are capable of detaching themselves from their affectsapproaching their patient's as both neutral and objective. This serves more as a flight from reality than an actual solution to the feared problem of affective bias. People are always enmeshed in some affect or other, even if it is only a mood (BT 389/340; Guignon 2009), or an ever-present feeling (Ratcliffe 2005, 2008, 2009a, b, 2014). As Halpern says, "emotions influence even seemingly detached beliefs and decisions" (Halpern 2001, p. 34). To suppose that this is not the case and that one is actually in a detached, neutrally affective state, it not to actually be in this state. Rather, it is to ignore the affects that are still present, affecting one's perceptions and judgments. Training physicians in detached concern weakens their abilities to attune to their affects, as well as the patient's affects (Green 2002, p. 255). Physicians are no more immune to their affects than anyone else and should not be treated as such.

When physicians fail to understand their own affective reactions to their patients, they risk projecting these affects onto their patients, thinking that they are being objective when they are not. When these reactions are negative, such 
as when patients are difficult and agitating, physicians "risk making poor decisions to alleviate their own distress" (Halpern 2014, pp. 305-306). ${ }^{14}$ All of their background affects and aspects of their own personal history are simply ignored in ST, which takes subjects to be largely interchangeable. If they have negative affective responses to their patient, then they are likely to avoid their patient.

Without attunement to their own affective reactions, this avoidance will be unintentional and therefore unlikely to be overcome. The physician will naturally try to avoid uncomfortable and difficult situations. Furthermore, if these negative affective responses continue unaddressed, then they can result in bias and prejudice. This can be problematic even with unacknowledged positive reactions to patients, but it is significantly more problematic when negative. The only way to overcome these problems is to be properly attuned to one's own affective responses and understand how these responses will affect their perceptions and judgments. As Halpern says, "recognizing how emotions influence judgment is part of a larger effort to cultivate skillful emotional communication in medical practice" (Halpern 2001, p. 29).

The third problem is that there is a lack of understanding for how affects influence our perceptions, beliefs, and judgments (Green 2002, p. 255; Halpern 2001, p. 27). This applies to both the physician and the patient. Concerning physicians, their lack of understanding for their own affects likewise means that they are unaware of how these affects are influencing them. When patients are difficult, inconvenient, or unlikeable, it can cause the physician to respond negatively (Coulehan et al. 2001, p. 222; Halpern 2007, p. 697). However, if they believe they are engaging with their patients in a detached, but caring way, while in fact they are being negatively affected by their own affective responses, then they will seriously risk treating their patients poorly without knowing it. As noted earlier, affects are everpresent. Ignoring them can cause physicians to avoid difficult patients, develop prejudices, and lead to errors in judgment (Halpern 2001, 2007).

Concerning patients, physicians are unable to understand how they are perceiving their own future possibilities and perceptions of their present state. As a simulation, even if it does luck into guessing the right affect to project onto the patient, there is still no further inclination to understand exactly how this affect is influencing the patient. For instance, physicians and nurses can believe that a patient is making an autonomous decision in refusing treatment. They

\footnotetext{
${ }^{14}$ Halpern warns against situations like this where there is a risk that "one person's irrational emotions are transmitted to others" (Halpern 2001, p. 9). This can happen when the patient is experiencing a strong emotion that is transmitted to the physician, but it can also happen when a physician transmits a strong emotion to the patient. It is the latter that is particularly troubling here.
}

may think this because they care about the patient, when imagining the patient's situation from their own perspectives, determine that they would also refuse treatment in a similar situation. However, this detached concern for the patient, and for the patient's overall situation does not actually get to the bottom of the patient's problems. There is no affective engagement, no communication, and no genuine understanding. They may fail to understand the ways that the patient's strong negative emotions in his or her dire situation may be seriously detracting from his or her autonomy.

Finally, detached concern leads to lack of trust and efficacy. As a result of the other three problems, as well as the continued primacy of the naturalistic attitude, we can generalize the problem of detached concern as the problematic lack of a genuine affective engagement with the patient. Detached concern carries "the presumption that a neutral, standardizable approach exists to meet patients' distress" (Halpern 2001, p. 25). It treats the patient as only existing for the physician in an intellectual way that "denies the ongoing emotional field between patients and physicians" (Halpern 2001, p. 25). The problem with this is that it "ignores the diverse needs of patients regarding emotional interactions with physicians" (Halpern 2001, p. 25). It assumes that the same rules and principles can be applied to each situation, but this is not the case.

This is evidenced by many cases when the principle of respecting autonomy-which is founded on a concern for the patient's wellbeing -is all that is followed, when other, more personal approaches may have been preferable. Physicians are always trained to be concerned for patient autonomy, but they lack any affective connection to their patients which could have caused them to care for more than just their abstract autonomy. There is no engagement with the patient's affects, the physician's own affects, nor how these affects influence the subjects. This lack of affective engagement causes a disconnect between patient and physician. Patients feel judged and handled rather than heard, understood, and cared for.

To summarize these problems, it can be argued that ST and detached concern cause the following problems:

(1) There is a lack of understanding for the patient's affects;

(2) There is a lack an attunement to the physician's own affective reactions to patients;

(3) There is a lack of understanding for the relationship between affects and beliefs; and

(4) There is a lack of affective engagement with the patient (Halpern 2001, p. 21).

From these problems, we can see that it is problematic and a complete distortion of the phenomenon of empathy to define it in absence of its affective aspects. According to Halpern, we need empathy to be genuine and not just a 
simulation (Halpern 2001, p. 88). By this, she means that the empathic understanding that one achieves should be a full understanding of the patient, the patient's situation, the physician's situation, and the interaction between them, rather than merely a simulation of the patient's mental states coupled with a projection of these perceived mental states back into the patient. "Genuine" identifies the understanding of the other as the other, whereas "simulation" denotes the understanding of the other as if oneself was the other. The continuation of the problem of detached concern in the acceptance of empathy signifies two things. First, it shows that we need a better theory of clinical empathy than STwe need a theory of empathy that will actually allow a more comprehensive understanding of the patient, as well as the affective relationships between the physician, patient, and the patient's situation. ${ }^{15}$ Second, it shows that the way in which empathy was accepted into medicine was such that other affective practices could not be accepted. While empathy itself is revalued in this shift, affectivity remains devalued. It is still understood as a problematic experience that physicians should avoid.

With the increasing desire for physicians who are more than just medical scientists, empathy was recommended as a skill that many thought would improve the relationship between physicians and patients. However, unwilling to reject the predominantly negative view of affectivity, empathy was merely appropriated into medicine, stripped of its affective dimension. This causes a tension between "whether empathy is an emotional engagement between patient and physician or is a purely intellectual form understanding patients" (Halpern 2001, p. 17). It is the latter that was the goal in medicine: a skill that can help the physician understand patients without any risk of the emotional attachments of sympathy (Aring 1958). This solves the problems of the lack of empathy, but in such a way that maintains the supposed objectivity of the field. As Halpern says, "the ideal of detached concerned is justified by the argument that only an unemotional physician is free to discern and meet patients'

\footnotetext{
15 I address one option for this in another paper (Hardy 2017). I argue that Shaun Gallagher's interaction theory is a promising alternative theory for clinical empathy. This theory explains the physician's understanding of patients from diverse backgrounds as an ability to learn and apply narratives. I find this to be a better theory of empathy because it provides a more holistic understanding of the patient and the patient's situation, in the sense that it incorporates both what the physician perceives of the patient and the patient's point of view on the patient. I do not explain this distinction here, since this paper is more concerned with sympathy than empathy. In other words, this paper is focused on the role that sympathy should play in medical practice if we continue to accept the current theory of empathy (rather than trying to redefine it). We could either redefine empathy to provide a more holistic understanding of the patient, or we can accept the current theory of empathy and incorporate a theory of sympathy to aid in the holistic understanding.
}

emotional needs without imposing his own" (Halpern 2001, p. 25). In effect, clinical empathy became the overly-cognitive detached concern, and sympathy became relegated to the overly-affective position empathy once held-as the subjective, affective response to the patient (Aring 1958; Blumgart 1964; Halpern 2001, p. 15, 18, 67).

However, this is really only a shift in terms and not a genuine solution to the problems caused by detached concern. The way in which physicians approach their patients is still as objects of scientific observation. It creates an environment in which patients are meant to be studied in order to learn the objective facts of their conditions. People, however, are not merely physical bodies, and they cannot be fully understood as such. Empathy as detached concern causes a false sense of understanding that can cause problems in diagnosis and treatment, as well as problems in affective understanding and engagement.

While it would be ideal to redefine clinical empathy in a way that allows it to be both cognitive and affective, this would be another project entirely. If nothing else, so long as empathy is defined as an understanding of the patient, then it will be lacking as an approach to treating the patient. It is incredibly useful and should certainly be part of medicine, but it cannot be expected to do all of the work. ${ }^{16}$ Empathy alone is not enough and must be supplemented with other experiences like sympathy and care (De Vignemont and Jacob 2012; Gelhaus 2012a, b, 2013; Svenaeus 2015). One serious worry, as Petra Gelhaus argues, is that "a perfect empathic understanding may very well be used for selfish or even malicious intentions" (Gelhaus 2012a, p. 110). Empathy, as an understanding of the other, could be used to either help people or harm them (or even to do nothing at all) (Gelhaus 2012b, p. 399). Scheler offers similar words of warning concerning his scenario of the cruel man. An understanding of the other can be used to save lives, but it can also be useful to the cruel man who understands the other's suffering and uses this understanding to inflict more suffering (Scheler 1954, p. 14). This is one of the reasons that Scheler argues for the importance of sympathy, and why Gelhaus argues that compassion is equally as important as empathy for the moral attitude of the physician.

To be fair, empathy is a necessary component of a moral attitude - "an anthropological precondition for morality, a necessary skill for good clinical action and decision-making, and also a moral-pragmatic activity" (Gelhaus 2012a, p. 111). Without empathy, there would be no basic understanding of the other from which to build more complex

\footnotetext{
${ }^{16}$ Some even argue that empathy serves as the foundation upon which all other intersubjective affective engagements are established, such as "pity, sympathy, affective matching, perspective taking etc., [which] arise at the secondary level" (Daly 2014, p. 231).
} 
understandings, and therefore no basis for moral action with respect to the other. However, it is worth cautioning here against taking the opposite track and arguing that empathy is necessarily moral. Empathy on its own will not make a physician a moral person. Other intersubjective affects like sympathy and care are necessary for a person to act morally.

In sum, when examining the problem of detached concern, it can be seen that empathy only came to be associated with detached concern as a way to incorporate it into the already established preference for cognitive approaches over affective approaches. That is, empathy was explained as a mere subjective feeling in traditional medicine, but was eventually redefined as a cognitive skill when it was needed for better patient care. ${ }^{17}$ This then left sympathy to fill the affective void left by empathy. Again, while empathy itself is revalued in this shift, affectivity remains devalued. It is still understood as a problematic experience that physicians should avoid. However, as demonstrated by the problems of detached concern explained above, this is incorrect. Affectivity has a vital role to play in the physician-patient relationship. This should not be a total acceptance of all affects at face value, but many affects do have a time and place where they are beneficial. The second half of this paper will focus on the role sympathy can and should play in medicine. While everyday sympathy - as defined earlier in this paper-can, in general, be both helpful and harmful, it is possible to refine everyday sympathy into a specifically clinical sympathy in the same way that empathy is being redefined as a specifically clinical empathy. If this can be done, sympathy can be rightly recommended as a trainable skill for medicine. The first step is to address the problems with everyday sympathy as a recommended clinical skill.

\section{The problems of sympathy}

There are at least five problems that can be identified with everyday sympathy that make it difficult to accept as useful for medical practice. The first problem has to do with the broadness of Scheler's definition and the way that it leads to an ambiguous moral fit of one's sympathy to the patient and situation. We can call this the Ambiguity Problem. As far as it has been defined here, we can divide sympathy into two forms: a negative or a positive emotional response towards the other's situation. As an aspect of our everyday reactions to others, we are always reacting towards others in positive

\footnotetext{
17 Paralleling and directly connected to the feeling/cognitive divide in the philosophy of emotion, this dichotomy between subjective feelings and objective cognitions can be shown to be both untrue and problematic. There is a need to overcome this divide and see both empathy and sympathy as affective phenomena that are important in and of themselves.
}

and negative ways-with anger, jealousy, contempt, pity, joy, love, excitement, and so one. It seems clear that it would be bad to react negatively to a patient-for instance, to be annoyed by a difficult patient such that you really just want to find a way to get rid of said patient.

Alternatively, it initially seems promising that positive emotional reactions to patients would be good-for instance, feeling happy about a patient's trust or about the initial successes of a treatment. However, even these affective responses to the patient can be dangerous to the patient's treatment. For instance, happiness about a patient's trust can easily devolve into paternalistic actions-choosing to treat patients in ways that they might not consent to if they were asked. Alternatively, joy at initial successes could be ill placed and cause physicians to be overly optimistic and not inquire fully into the negative effects the treatment may be having on the patient.

The point here is that emotions can be either beneficial or costly depending on the circumstances. This does not mean that affects should be completely avoided, but it also does not mean that they should be blindly accepted in all situations. Ideally, it would be best that physicians train themselves to have the right emotional responses, to the right patients, at the right time. Since sympathy is our affective response and relatedness to the other, and we can never fully escape our affects, the ideal would be to train the best possible emotional reactions. However, this is little help to those who do not yet have the right affective habits. This leads to the next problem.

It is not common that we control our sympathetic reactions. Even if it may be bad to be annoyed by a difficult patient, that does not make it possible suddenly will oneself out of such an annoyance. Emotions and feelings are experiences that take place below the level of our will (Merleau-Ponty 2012, p. 166). We can call this the Control Problem. We do not control them and we cannot simply make them go away once we are experiencing them. However, this also means that we cannot choose to simply not experience affects. Affects are an ever-present aspect of our lives. Rather than suppose that we can think them away or think specific affective responses into being, it would be better to be aware of our emotional responses to others and how they may be affecting us. Irritation with a patient is not itself a problem-it is a clue that there is something wrong that needs to be addressed. ${ }^{18}$ In this sense, clinical sympathy

\footnotetext{
18 This is similar to how Halpern talks about the emotional resonance that she argues is an aspect of empathy. She says that emotional resonance is the physician's first clue to understanding the patient's "emotional point of view" (Halpern 2001, p. 16). It is the physician's attunement to the patient's relationship to the world It immediately established the patient's affects "as presences, rather than as mere possibilities" (Halpern 2001, 74). However, many physician's pass over and ignore the opportunity to explore this clue because they
} 
would need to be neither passive nor requiring complete control. Instead, it would need to be reflective.

The last three of these problems are drawn from Gelhaus's article on compassion, with which sympathy shares many of the same issues (Gelhaus 2012b, p. 402). For the issues that Gelhaus notes, it is worth examining the similarities and differences between sympathy and compassion. Gelhaus defines compassion very similar to how Scheler defines sympathy-it is "a certain emotional response to the experienced suffering of another person" (Gelhaus 2012b, p. 399). ${ }^{19}$ She likewise makes a distinction between everyday compassion and professional compassion-or what I have called sympathy and clinical sympathy. Everyday compassion is characterized as being a warm, spontaneous emotional response to the other (Gelhaus 2012b, p. 399). This is when we feel very strongly for or about others and their emotional states. The primary difference between Scheler's theory and Gelhaus's is that Gelhaus thinks there is a necessary aspect of benevolence to compassion (Gelhaus 2012b, p. 399), while Scheler thinks that sympathy can be either benevolent or malevolent - the subject can either feel sadness or joy at the other's suffering. We might be able to say that compassion is a subcategory of sympathy-specifically that subcategory of positive emotional responses. However, even when interpreted as an entirely benevolent experience, Gelhaus still does not think that this is the right kind of compassion for medical professionals. For my purpose, I will rephrase many of her comments in terms of sympathy rather than compassion.

The third problem, adapted from Gelhaus's article, can be called the Overstraining Problem. This refers to the problem of professional burnout, such as when physicians become too emotionally invested in their patients, and become emotionally strained when they are unable to help (Gelhaus 2012b, p. 401). Physicians see many patients each day and it can be emotionally exhausting to connect with all of them. To form sympathetic connections with all patients would cause elation at successful treatments and disappointment when patients die or refuse to take advice. This ebb and flow between joy and sadness, hope and disappointment, and so on, takes a toll on a physician. It is easy to burnout on one's sympathetic reactions such that it becomes more difficult to sympathize as the days and weeks go on. This has consistently been one of the worries about affective experiences in medicine (Eikeland et al. 2014; Hooker 2015). However, it

\section{Footnote 18 (continued)}

focus too narrowly on facts, rather than to "the emotional meanings of patients' words" (Halpern 2007, 697).

${ }^{19}$ It is also worth noting that Gelhaus defines sympathy in the way that Scheler defines emotional contagion- "sharing the same feelings with the other" (Gelhaus 2012b, p. 399). may be ill-placed, since it has also been shown that empathy (and affective experience) can actually lead to greater fulfillment and reduce professional burnout (Eikeland et al. 2014, p. 1; Gelhaus 2012b, p. 401; Halpern 2014, p. 304; Larson and Yao 2005; Shanafelt et al. 2005).

The fourth problem refers to the way that a compassionate attitude could become, or at least be perceived as, pity (Gelhaus 2012b, p. 401-402). We can call this the Condescension Problem. That is, feeling bad about the patient's situation could make the patient feel like the physician is looking down on him or her. This can lead to the patient acting more standoffish and therefore more difficult to treat. Aside from compassion and pity, other affective responses to patients can be equally perceived as condescending. If the patient feels the physician's annoyance or anger, the patient could perceive this as judgment and refuse to work with the physician any further. Condescension can damage trust and lead to a more resistant patient. While it should be understood that physicians are not entirely responsible for the way in which patients respond to them and interpret their actions, it would still be helpful if clinical sympathy could cause less of a feeling of condescension. It should at least result in active treatments instead of mere pity-behaviors.

The final problem refers to the inability to express the same level of compassion towards all patients in the same way (Gelhaus 2012b, p. 402). We can call this the Injustice Problem. Physicians will often feel more sympathy towards some patients than others, but how can this be morally permissible? Sympathy is a kind of emotional investment in others, but physician may not have the time or the emotional resources to invest the same amount in all their patients. Should some patients receive more sympathetic care than others? It is certainly the case that some patients warrant more of an emotional response and engagement than others based on their conditions. However, everyday sympathy may simply give more of an emotional response to others who are similar to the physician or that have conditions with which the physician is more familiar. This would not be fair to all patients.

If we are going to refine a specifically clinical sympathy, then all five of these problems need to be overcome. Here is a brief summary of the problems as explained above:

1. Ambiguity - The ambiguous moral fit of one's sympathy to the patient and situation.

2. Control-The lack of control over the form of sympathy one experiences.

3. Overstraining-The overstraining of the physician's affects that could lead to burnout.

4. Condescension-The risk of the physician's sympathy being perceived as condescending.

5. Injustice-The injustice in the levels of sympathy experienced for different patients. 
I agree with Gelhaus that it may be possible to overcome some of these problems if we set aside the idea of sympathy in the everyday sense, as the "usual spontaneous unprocessed emotion" (Gelhaus 2012b, p. 402). Physicians need to maintain the morally useful aspects of everyday sympathy and use them to create a more professional attitude (Gelhaus 2012b, pp. 399, 403).

Sympathy is useful to medicine in that it connects physicians to their patient and moves them to help their patients in a way that is lacking with a purely naturalistic, objective, scientific approach to patients. The problems only arise with sympathy when it is allowed to function blindly as a background emotion. In these situations, physicians are still being affected by their sympathy, but they are not conscious of the ways in which they are being affected. They believe they are being objective when they are not. Rather than stripping sympathy of its affectivity in the way that empathy has been, the goal in the final section is to provide a theory of clinical sympathy that is useful for better patient care and trainable for physicians, while maintaining it as an affective experience.

\section{Clinical sympathy}

Clinical sympathy can now be defined as such:

Clinical sympathy: a reflective, affective response to the patient, where the reflection couples an attunement to one's own affective response with an understanding of how one's affects are influencing one's beliefs and judgments.

All three of these features of clinical sympathy are necessary for it to be useful for physicians:

\section{Affective response}

2. Attunement to one's own affective response

3. Understanding of the influence the affective response has on beliefs and judgments.

This neither ignores one's affects nor does it ignore the ways that these affects can be important guides in decisionmaking. In this form, clinical sympathy can overcome many of the problems from the previous section.

To begin with, ambiguity is not a problem because clinical sympathy accepts that all affective responses can be useful guides for understanding. In other words, the physician's affective response is an important clue to the relationship between physician and patient. In this sense, all affective reactions fit the situation, since they inform the physician about something important: the initial standing of the relationship between physician and patient. Whether or not an affect is morally useful is not decided by luck, but rather by understanding the influences of the affect and being able to reflect on the reasons that contributed to one's affective response. If physicians are frustrated by their patients, they can investigate why they are having this affective response and actually address the problem in their relationship rather than just ignoring it. In the reflection and understanding, all affective responses can be made morally useful.

Similarly, a lack of control over one's affects is not a problem for clinical sympathy since one of the purposes of clinical sympathy is the acknowledgement that we do not have control over our affects. They are beneath the level of the will. The best we can do is acknowledge them and be aware of the ways that they are influencing us. In other words, we do not have control over our initial sympathy, but what we can control is the way that we respond to our own sympathy. Clinical sympathy overcomes the control problem by actually engaging with one's affective response and reacting to them accordingly. In this sense, acknowledging affects in clinical sympathy provides more control than ignoring sympathy.

Overstraining should not be an issue for clinical sympathy either, since there is more of an awareness of the emotional ties that the physician has to the patient. As noted earlier, it has been shown that experiencing affects towards patients does not necessarily lead to emotional or professional burnout; in fact, it can actually lead to a greater sense of fulfillment. Burnout can be attributed to both cognitive and affective activities when taken to excess. When we require awareness and reflection, there is a greater chance that physicians can avoid both over-attachment through their emotions and over-thinking a situation with their cognitive abilities. Again, we are always experiencing affects even if we are not explicitly aware of them. This means that the emotional connection either happens and has an effect without the physician being aware of it or it happens, the physician is aware of it, and the physician can be more cautious about the effects of their affective connection. As with control problem, overstraining can only be overcome with awareness, not by ignoring affects.

Condescension could still be a problem since, as mentioned earlier, physicians can never fully control the reactions of their patients. A physician could do everything right and still be perceived as condescending by a patient. The hope with clinical sympathy is that a physician who is reflective of their affective responses can lessen the chance of condescension by curving the expression of their affects. For instance, if they are annoyed with a patient, they can be aware of their affective response while also focusing on not acting annoyed. However, there will always be the possibility that expressions will slip through and that the physician will be perceived as condescending. For this problem to truly be avoided, it will be important for sympathy to be combined with other skills like clinical empathy.

Finally, injustice should not be an issue, since affective responses are always present and physicians can always be 
reflective of their affective response with all of their patients. In other words, no one patient is receiving more of a sympathetic response than another, since there is always an affective response. These affective responses are then used as clues to further engage with patients in different ways depending on the affect. This may lead to some patients receiving more attention than others, but two points should be made about this. First, it is not the sympathy itself that is being paid more to one patient over another-it is the treatment and communication being given to a patient based on both sympathy and the patient's condition. Second, patients already receive different amounts of attention and care based on the severity of their conditions. This is not injustice, but simply a necessary feature of medicine due to the limited time and resources of physicians. Sympathy is just another resource that can be tapped in similar ways.

At this point, it still needs to be noted that clinical sympathy has two lingering problems. ${ }^{20}$ The first is that there is a problem with requiring physicians to experience affects. As Gelhaus says, "though we might prefer persons as healthcare professionals who are talented for compassion and feel it rather often for their patients, it is useless to demand it in the cases when it is absent" (Gelhaus 2012b, p. 402). Requiring affects can lead to physicians simply acting like they are experiencing compassion, or cause them to become resentful and annoyed at forcing an affective experience. It is very difficult to simply will oneself into a new affect, and it would be unrealistic to require physicians to do so.

The second problem is the asymmetry involved in sympathy (Gelhaus 2012b, p. 404). Due to the nature of the clinical encounter, compassion is set up to be an experience that physicians have for their patients, but not the other way around. However, this seems to be an unavoidable consequence of sympathy. As Gelhaus says, "there is no chance to guard the morally good aspects of [sympathy] and at the same time to make it something symmetrical that focuses on direct mutuality" (Gelhaus 2012b, p. 404). Because sympathy leads one to approach the other in a specific way regardless of the patient's actions, it must be one-sided-or it at least cannot be required that the patient reciprocate.

\section{Conclusion}

The revaluation of empathy, while a step in the right direction, was actually a misstep in its implementation. By continuing in the vein of the naturalistic attitude by giving excessive weight to cognitive skills over affective experiences, the problems of detached concern were readopted

\footnotetext{
20 These are also identified by Gelhaus in her discussion of compassion as a professional attitude.
}

into medicine, albeit in a new form. If medical professionals are going to surpass the problem of detached concern and improve patient care, we need to revalue affectivity and not appropriate affects into the accepted naturalistic attitude. One positive step that can be made towards clinical affectivity is refining sympathy into a specifically clinical skill. In developing this clinical sympathy, it is important to maintain the affective dimension of sympathy.

The reason that sympathy needed to be refined is because everyday sympathy does suffer from several ethical problems. These include ambiguity, lack of control, overstraining, condescension, and injustice. When clinical sympathy is defined as an affective response to patients, in which physicians are both attuned to their affective response and understand how their affects are influencing their beliefs and judgments, it is capable of avoiding many of these issues. However, even clinical sympathy is vulnerable to some additional issues. Principle among them are the problems of requiring sympathy and the asymmetry in the way sympathy is experience by physician and patient.

At this point, as with empathy, it needs to be admitted that sympathy alone is not enough. In fact, Gelhaus cautions against being too closely emotionally involved in a patient's life (Gelhaus 2012a, p. 107). This is because too strong of an emotional pull can cause one to act towards patients in a way that may be overly paternalistic and/or harmful. Gelhaus believes that this may happen if physicians only possess sympathy, but not empathy (Gelhaus 2012b). ${ }^{21}$ On its own, sympathy can lead to paternalistic actions that do not fully understand the patient's views on his or her own situation. For instance, there is the risk of "death angels" who end the lives of patients for whom they are very sympathetic (Foss 2006). They do this because they feel so deeply for their patients that they cannot bear to see their patients suffer any longer, but that does not make the taking of a life any less ethically problematic. When combined with empathy, however, sympathy "recognizes needs and moves the doctor to react in a kind and respectful way in order to help" (Gelhaus 2012b, p. 406). Together, they provide physicians with both an understanding of their patients and a benevolent emotional connection to their patients. However, even when taken together, they may still be deficient (Gelhaus 2012b, p. 400).

Empathy and sympathy are not the only ways to improve patient care and this paper has not presented them

\footnotetext{
21 This goes back to the divide between detached concern and sympathy. These are established as extremes in medicine, where sympathy is an overly strong emotional engagement with the patient and detached concern is devoid of emotional engagement. Detached concern can easily lead to unwarranted paternalism, whereas sympathy risks leading to either paternalism or avoidance, based on the physician's affective response to the other.
} 
as such. Rather, this paper argues that there is a need to expand beyond mere detached concern and the naturalistic attitude. We need to open medicine to other, supplemental approaches like empathy, sympathy, and care. When this is done, there will be a better environment in medicine that is more open to exploring other supplemental approaches as well as affectivity. While the theory of clinical sympathy presented in this paper, may still be vulnerable to some objections, it will hopefully encourage further discussion and refinement of theories of sympathy such that a viable definition for clinical sympathy can be recommended for medical professionals in the near future.

\section{References}

Aring, Charles. 1958. Sympathy and empathy. Journal of the American Medical Association 167 (4): 448-452.

Baron-Cohen, Simon. 1993. The concept of intentionality: Invented or innate? Behavioral and Brain Sciences 16 (1): 29-30.

Baron-Cohen, Simon. 1995. Mindblindness: An Essay on Autism and Theory of Mind. Cambridge, MA: MIT Press.

Blumgart, Herrman. 1964. Caring for the patient. The New England Journal of Medicine 270 (9): 449-456.

Cadge, Wendy and Clare Hammonds. 2012. Reconsidering detached concern: The case of intensive-care nurses. Perspectives in Biology and Medicine 55 (2): 266-282.

Carel, Havi. 2011. Phenomenology and its application in medicine. Theoretical Medicine and Bioethics 32 (1): 33-46.

Coulehan, John L, et al. 2001. "Let me see if I have this right... Words that help build empathy. Annals of Internal Medicine 135 (3): 221-227.

Daly, Anya. 2014. Primary intersubjectivity: Empathy, affective reversibility, 'self-affection' and the primordial 'we.'. Topoi 33: $227-241$.

De Vignemont, Frédérique, and Pierre Jacob. 2012. What is it Like to feel another's pain? Philosophy of Science 79 (2): 295-316.

Derksen, Frans, Jozien Bensing, and Antoine Lagro-Janssen. 2013. Effectiveness of empathy in general practice: A systematic review. British Journal of General Practice 63 (606): e76-e84.

Di Blasi, Zelda, and Jos Kleijnen. 2003. Context effects: Powerful therapies or methodological bias? Evaluation and the Health Professions 26: 166-179.

Eikeland, Hanne-Lise, et al. 2014. The physician's role and empathy-A qualitative study of third year medical students. $B M C$ Medical Education 14: 165-172.

Ekman, Eve, and Jodi Halpern. 2015. Professional distress and meaning in health care: Why professional empathy can help. Social Work in Health Care 54 (7): 633-650.

Flaherty, Lauren. 2016. Empathetic reasoning as an evolution of humankind. Dialogue: 113-121.

Foss, T. D. 2006. Angels of death? Mercy killing? How about murder? British Journal of Nursing 15 (8): 417.

Fox, Renée C. 1959. Experiment Perilous: Physicians and Patients Facing the Unknown. Glencoe, IL: Free Press.

Fox, John. 2006. Notice how you feel": An alternative to detached concern among hospice volunteers. Qualitative Health Research 16 (7): 944-961.

Gallagher, Shaun. 2001. The practice of mind: Theory, simulation, or interaction? Journal of Consciousness Studies 8 (5-7): 83-107.
Gallagher, Shaun. 2004. Understanding interpersonal problems in autism: Interaction theory as an alternative to theory of mind. Philosophy, Psychiatry, \& Psychology 11 (3): 199-217.

Gallagher, Shaun. 2009. Two problems of intersubjectivity. Journal of Consciousness Studies 16 (6-8): 289-308.

Gallagher, Shaun. 2012. Empathy, simulation, and narrative. Science in Context 25 (3): 355-381.

Gallagher, Shaun, and D Hutto Daniel. 2008. Understanding others through primary interaction and narrative practice. In The Shared Mind: Perspectives on Intersubjectivity, eds. J. Zlatev, T. Racine, C. Sinha, and E. Itkonen, 17-38. Amsterdam: John Benjamins.

Gallese, Vittorio. 2001. The "shared manifold" hypothesis from mirror neurons to empathy. Journal of Consciousness Studies 8 (5-7): $33-50$.

Gallese, Vittorio. 2003. The roots of empathy: The shared manifold hypothesis and the neural basis of intersubjectivity. Psychopathology 36 (4): 171-180.

Garden, Rebecca. 2007. The problem of empathy: Medicine and the humanities. New Literary History 38 (3): 551-567.

Gelhaus, Petra. 2012a. The desired moral attitude of the physician: (I) Empathy. Medicine, Health Care and Philosophy 15: 103-113.

Gelhaus, Petra. 2012b. The desired moral attitude of the physician: (II) Compassion. Medicine, Health Care and Philosophy 15: 397-410.

Gelhaus, Petra. 2013. The desired moral attitude of the physician: (III) Care. Medicine, Health Care and Philosophy 16: 125-139.

Goldman, Alvin. 2006. Simulating Minds. New York: Oxford University Press.

Goldman and Sripada. 2005. Simulationist models of face-based emotion recognition. Cognition 94 (3): 193-213.

Gopnik, Alison. 1988. Conceptual and semantic development as theory change. Mind and Language 3 (3): 197-216.

Gopnik, Alison. 1993. How we know our minds: The illusion of firstperson knowledge of intentionality. Behavioral and Brain Sciences 16 (1): 1-14.

Gopnik, Alison. 1996. The scientist as child. Philosophy of Science 63 (4): 485-514.

Gopnik, Alison, and N Meltzoff Andrew. 1997. Words, Thoughts, and Theories. Cambridge, MA: MIT Press.

Gopnik, Alison and Laura Schulz. 2004. Mechanisms of theory formation in young children. TRENDS in Cognitive Sciences 8 (8): 371-377.

Gopnik, Alison, and Henry M. Wellman. 1992. Why the child's theory of mind really is a theory. Mind \& Language 7 (1-2): 145-171.

Green, Stephen. 2002. Review of Jodi Halpern, From Detached Concern to Empathy: Humanizing Medical Practice. Psychosomatics 43 (3): $255-256$.

Guignon, Charles. 2009. The body, bodily feelings, and existential feelings: A Heideggerian perspective. Philosophy, Psychiatry, \& Psychology 16 (2): 195-199.

Halpern, Jodi. 2001. From Detached Concern to Empathy: Humanizing Medical Practice. New York: Oxford University Press.

Halpern, Jodi. 2003. What is clinical empathy? Journal of General and Internal Medicine 18: 670-674.

Halpern, Jodi. 2007. Empathy and patient-physician conflicts. Journal of General Internal Medicine 22 (5): 696-700.

Halpern, Jodi. 2011. Clinical empathy. In From Bench to Bedside: Empathy and the Social Brain. ed. Decety Jean. Cambridge, MA: MIT Press.

Halpern, Jodi. 2012. Attending to clinical wisdom. Journal of Clinical Ethics 23 (1): 41-46.

Halpern, Jodi. 2014. From idealized clinical empathy to empathic communication in medical care. Medicine, Health Care and Philosophy 17: 301-311.

Hardy, Carter. 2017. Empathizing with patients: The role of interaction and narratives in providing better patient care. Medicine, Health Care and Philosophy 20 (2): 237-248. 
Heidegger, Martin. 1962. Being and Time. Translated by John Macquarrie and Edward Robinson. New York: Harper \& Row.

Hojat, Mohammadreza, et al. 2009. The devil is in the third year: A longitudinal study of erosion of empathy in medical school. Academic Medicine 84 (9): 1182-1191.

Hojat, Mohammadreza, et al. 2011. Physicians' empathy and clinical outcomes for diabetic patients. Academic Medicine 86: 359-364.

Hojat, Mohammadreza, et al. 2013. Empathy and health care quality. American Journal of Medical Quality: The Official Journal of the American College of Medical Quality 28 (1): 6-7.

Hooker, Claire. 2015. Understanding empathy: Why phenomenology and hermeneutics can help medical education and practice. Medicine, Health Care and Philosophy 18: 541-552.

Karmiloff-Smith, Annette. 1988. The child as theoretician, not an inductivist. Mind and Language 3 (3): 183-195.

Khanuja, S., et al. 2011. Empathy and sympathy in the medical profession: Should we stop the desertion? Pravara Medical Review 3 (3): 37-39.

Kitcher, Philip. 1988. The child as parent of the scientist. Mind and Language 3 (3): 217-228.

Lampert, Bettina, and Glaser Jürgen. 2016. Detached concern in client interaction and burnout. International Journal of Stress Management. https://doi.org/10.1037/str0000053. (Advance online publication)

Landes, Donald A. 2012. Translator's introduction. In Phenomenology of Perception, Maurice Merleau-Ponty, Translated by Donald A. Landes: $x x x$-li. New York: Routledge.

Lanzoni, Susan. 2012. Empathy in translation: Movement and image in the psychological laboratory. Science in Context 25 (3): 301-327.

Larson, Eric B., and Xin Yao. 2005. Clinical empathy as emotional labour in the patient-physician relationship. JAMA 293 (9): 1100-1106.

Lief, Harold, and Fox Renée. 1963. Training for "detached concern" in medical students. In The Psychological Basis of Medical Practice, ed. H. Lief, 12-35. New York: Harper \& Row.

Macnaughton, Jane. 2009. The dangerous practice of empathy. The Lancet 373: 1940-1941.

Marcus, E. R. 1999. Empathy, humanism and the professionalisation process of medical education. Academic Medicine 74: 1211-1215.

Meltzoff, Andrew N. 2006. The 'like me' framework for recognizing and becoming an intentional agent. Acta Psychologica 124: 26-43.

Merleau-Ponty, Maurice. 2012. Phenomenology of Perception. Translated by Donald A. Landes. New York: Routledge.

Merton, Robert. 1957. The Student-Physician: Introductory Studies in the Sociology of Medical Education. Cambridge: Harvard University Press.

Osler, William. 1899. Address to the students of the Albany Medical College. Albany Medical Ann 20: 307-309.

Osler, William. 1904. Aequanimitas. In Aequanimitas, With Other Addresses to Medical Students, Nurses and Practitioners of Medicine, 1-11. Philadelphia: P. Blakiston's.

Pedersen, Reidar. 2008. Empathy: A wolf in sheep's clothing? Medicine, Health Care and Philosophy 11: 325-335.

Pedersen, Reidar. 2010. Empathy development in medical educationA critical review. Medical Teacher 32: 593-600.
Pinotti, Andrea. 2010. Empathy. In Handbook of Phenomenological Aesthetics, ed. Hans Rainer Sepp and Lester Embree, 93-98. Dordrecht: Springer.

Ratcliffe, Matthew. 2005. The feeling of being. Journal of Consciousness Studies 12 (8): 43-60.

Ratcliffe, Matthew. 2008. Feelings of Being: Phenomenology, psychiatry and the sense of reality. Oxford: Oxford University Press.

Ratcliffe, Matthew. 2009a. Belonging to the world through the feeling body. Philosophy, Psychiatry, \& Psychology 16 (2): 205-211.

Ratcliffe, Matthew. 2009b. Existential feeling and psychopathology. Philosophy, Psychiatry, \& Psychology 16 (2): 179-194.

Ratcliffe, Matthew. 2014. Why mood matters. In The Cambridge Companion to Heidegger's 'Being and Time', ed. Mark A. Wrathall, 157-176, Cambridge: Cambridge University Press

Roter, Debra L., et al. 2006. The expression of emotion through nonverbal behavior in medical visits: Mechanisms and outcomes. Journal of General Internal Medicine 21: S28-S34.

Scheler, Max. 1954. The Nature of Sympathy. Translated by Peter Heath. London: Routledge \& Kegan Paul LTD.

Scheler, Max. 1992. On Feeling, Knowing and Valuing. Chicago: University of Chicago Press.

Shanafelt, Tait D., et al. 2005. Relationship between increased personal well-being and enhanced empathy among internal medicine residents. Journal of General Internal Medicine 20: 559-564.

Singh, Sonal. 2005. Empathy: Lost or found in medical education? Medscape General Medicine 7 (3): 74.

Skeff, Kelley M., and Sunita Mutha. 1998. Role models: Guiding the future of medicine. New England Journal of Medicine 339: 2015-2017.

Svenaeus, Fredrik. 2015. The relationship between empathy and sympathy in good health care. Medicine, Health Care and Philosophy 18: 267-277.

Testerman, J. K., K. R. Morton, L. K. Loo, J. S. Worthley, and H. H. Lamberton. 1996. The natural history of cynicism in physicians. Academic Medicine 71 (10): S43-S45.

Underman, Kelly and Laura Hirshfield. 2016. Detached concern? Emotional socialization in twenty-first century medical education. Social Science \& Medicine 160: 94-101.

Vandenberghe, Frédéric. 2008. Sociology of the heart: Max Scheler's epistemology of love. Theory, Culture and Society 25 (3): 17-51.

Wellman, Henry. 1990. The Child's Theory of Mind. Cambridge, MA: MIT Press.

Wellman, Henry, David Cross, and Julanne Watson. 2001. Meta-analysis of theory-of-mind development: The truth about false belief. Child Development 72 (3): 655-684.

Yagil, Dana, and Moran Shnapper-Cohen. 2016. When authenticity matters most: Physicians' regulation of emotional display and patient satisfaction. Patient Education and Counseling 99: 1694-1698.

Zahavi, Dan. 2014a. Empathy and other-directed intentionality. Topoi 33: $129-142$.

Zahavi, Dan. 2014b. Self and Other: Exploring Subjectivity, Empathy, and Shame. Oxford: Oxford University Press. 